\title{
Minimally Invasive Gynecological Surgery under Local Anesthesia
}

\author{
Ahmed Altraigey ${ }^{1 *}$ and Samar Rafik ${ }^{2}$ \\ ${ }^{1}$ Department of Obstetrics and Gynecology, Benha University, Egypt \\ ${ }^{2}$ Department of Anaesthesia, Benha University, Egypt
}

Submission: April 01, 2019; Published: April 17, 2019

*Corresponding author: Ahmed Altraigey, 43 Benha Zagzig Street, Mansheyet Elnoor, Benha Qalubeya Arab, Republic of Egypt

Keywords: Laparoscopic surgery; Local anesthesia; Tubal ligation; Ovarian cyst; Ectopic pregnancy; Pelvic pain

\section{Mini Review}

Laparoscopic surgery is universally used as a principle technique for minimally invasive abdominal surgery. It was implemented and standardized in wide range of procedures across multiple surgical specialties. Gynecological surgeries were among its first applications including; tubal ligation, ovarian cyst removal, management of ectopic pregnancy, exploration of chronic pelvic pain, infertility and treatment of endometriosis. Laparoscopy's advantages in comparison to open abdominal surgery included lower surgical trauma, less pain occurrence, less post-operative respiratory complications and shorter recovery time as well as hospital stay. The cons included longer surgical times, slower learning curves and higher equipment costs [1]. Three techniques of anesthetic management can be utilized in gynecologic laparoscopy; general anesthesia, regional and local with or without conscious sedation. Whatever the choice, it is mandatory to allow the surgeon to operate safely and adequately, and the patient should recover quickly and with fewer side effects [2].

Traditionally, laparoscopic procedures were carried out under General Anesthesia (GA) due to the pulmonary functions' changes occurred as a result of pneumoperitoneum, which is a crucial step of laparoscopy. The accurate control of ventilation under GA was proven to be optimum for such procedures. However, the use of Local Anesthesia (LA) emerged recently as an alternative tool for laparoscopy to overcome complications of GA [3].

In the last two decades, the use of LA with conscious sedation was limited to certain procedures as diagnostic laparoscopy, mini-laparoscopy, and minor surgical procedures. The main obstacles encountered were difficulties exposing the surgical field and patient cooperation issues. In 2015, a case series described five cases of laparoscopic salpingo-oophorectomy that were successfully performed under LA and total intravenous sedation protocol, depending on continuous propofol and remifentanil infusion. Authors first labeled this technique with the acronym OLICS (Operative Laparoscopy in Conscious Sedation) and reported using LA in operative laparoscopy [4].

Combination of conscious sedation with LA infiltration at the site of cannula entry was beneficial during the procedure. According to the American Society of Anesthesiologists (ASA), conscious sedation was defined as a drug-induced depression of consciousness that keep the patient calm, awake and responsive to follow verbal orders, either alone or associated with light tactile stimulus. No further intervention was needed to maintain normal respiratory and cardiovascular function. Sedation is used to decrease patient anxiety which sometimes induce arrhythmia and patient discomfort which lead to involuntary movements that can obstruct handling the operative site properly and negatively affect the surgeon's performance. Also, it encourages patient cooperation during the procedure [5].

LA revealed multiple advantages over GA, such as shorter anesthesia and recovery times and less postoperative nausea and vomiting. This faster recovery was associated with shorter hospital stay and, decreased costs and needs for admitting patients in post anesthesia care unit. Moreover, verbal contact with the patient could improve identification of certain complications. Patients might indicate region of pain that would help the surgeon to detect which lesions were painful and needed interference and which do not. This maneuver of conscious pain mapping was the only laparoscopic procedure that cannot be conducted under GA [6].

Some disadvantages of LA were its deficient use in operative laparoscopy due to, anxiety and discomfort for some patients especially during manipulation of abdominal and pelvic organs, Moreover, delayed management of complications that require GA. This necessitates the availability of emergency drugs and equipment in case laparotomy becomes crucial decision. Morbid 
obesity, suspicion intra-abdominal adhesions, extensive peritoneal irritation, uncooperative patients were contraindications to LA [7].

Monitoring is fundamental for early recognition of complications. Both sedation and pneumoperitoneum could lead to hypoventilation and hypoxia. Therefore, pulse oximetry is essential even PETCO2 should be monitored cautiously during laparoscopy under LA. Børdahl et al. [8], reported that patients receiving conscious sedation were subjected to more apnea episodes during the procedure compared with GA; this observation disappeared after the patients received $3 \mathrm{~L}$ oxygen during operation. The patients' degrees of awareness and sedation were followed by maintaining verbal contact [8].

Recently, a systematic review compared laparoscopic sterilization under LA with conscious sedation versus GA, showed that both anesthetic techniques were comparable regarding operation times, postoperative pain, and complications. Furthermore, LA with conscious sedation offered better results in respect to terms of recovery times, patient sore throat complaints as well as patient recovery and satisfaction compared with GA [9].

To achieve the success of such procedure under LA, various factors should be considered; importantly setting of appropriate patient selection criteria, such as high body mass index, intraabdominal adhesions and anxiety that could limit LA use. Also, a highly skilled surgeon with laparoscopic experience and quick execution of the surgical technique is a prerequisite to make the procedure feasible. In almost all cases reported, operative time was approximately 20 minutes. Another key element was the use of low-pressure pneumoperitoneum. The use of a maximum $8 \mathrm{mmHg}$ CO2 pressure may minimize postoperative abdominal and shoulder pain as well as reducing cardiopulmonary disorders caused by high pressures [4].

Unfortunately, information regarding this subject is relatively old and scanty. Most of the studies were carried out at least 20 years ago. So, questions about the relevance of these studies have been emerged and how to optimize our observations in recent

This work is licensed under Creative Commons Attribution 4.0 License DOI: 10.19080/JAICM.2019.08.555747 years. For example, more specialized and small sized instruments for laparoscopic surgery have been introduced nowadays, which might affect the outcome. As well as, the drugs used for anesthesia and sedation in some studies were different from the drugs used today [9].

New researches concerning this issue are required to optimally advise our patients about the best anesthetic technique they can choose for a laparoscopic intervention. Also, healthcare professionals including both gynecologists and anesthesiologists could benefit from these data to fasten the performance of the surgical procedures and decrease the risks for the patient.

\section{References}

1. Smith I (2001) Anesthesia for laparoscopy with emphasis on outpatient laparoscopy. Anesthesiol Clin North Am 19(1): 21-41.

2. Coskun F (1999) Anesthesia for gynecologic laparoscopy. The Journal of the American Association of Gynecologic Laparoscopists 6(3): 245258.

3. Gerges FJ, Kanazi G, Jabbour-khoury S (2006) Anesthesia for laparoscopy: a review. J Clin Anesth 18(1): 67-78.

4. Rosati M, Bramante S, Conti F, Rizzi M, Frattari A, et al. (2015) Laparoscopic salpingo-oophorectomy in conscious sedation. JSLS: Journal of the Society of Laparoendoscopic Surgeons 19(3).

5. (1999) Continuum of depth of sedation: definition of general anesthesia and levels of sedation/analgesia. American Society of Anesthesiologists. Approved by ASA House of Delegates on October 13, 1999, and last amended on October 15, 2014.

6. Nezhat C, Main J, Paka C, Soliemannjad R, Parsa MA (2014) Advanced gynecologic laparoscopy in a fast-track ambulatory surgery enter. JSLS 18(3): 1-5.

7. Gupta L, Sinha SK, Pande M, Vajifdar H (2011) Ambulatory laparoscopic tubal ligation: a comparison of general anaesthesia with local anaesthesia and sedation. J Anaesthesiol Clin Pharmacol 27(1): 97-100.

8. Børdahl PE, Raeder JC, Nordentoft J, Kirste U, Refsdal A (1993) Laparosocpic sterilization under local or general anesthesia? A randomized study. Obstet Gynecol 81(1): 137-141.

9. Huppelschoten AG, Bijleveld K, Braams L, Schoot BC, Van Vliet HA (2018) Laparoscopic sterilization under local anesthesia with conscious sedation versus general anesthesia: Systematic review of the literature. Journal of minimally invasive gynecology 25(3): 393-401.

\section{Your next submission with Juniper Publishers will reach you the below assets}

- Quality Editorial service

- Swift Peer Review

- Reprints availability

- E-prints Service

- Manuscript Podcast for convenient understanding

- Global attainment for your research

- Manuscript accessibility in different formats

( Pdf, E-pub, Full Text, Audio)

- Unceasing customer service

Track the below URL for one-step submission https://juniperpublishers.com/online-submission.php 